DOI: $10.1515 /$ abcsj-2014-0027

\title{
Seeing the Novel, Reading the Film: Unveiling Masculinity, Englishness and Power Struggle in Arthur Conan Doyle's
}

\author{
The Hound of the Baskervilles
}

\author{
IRINA I. SIMONOVA STROUT
}

The University of Tulsa

\begin{abstract}
Masculinity as a notion encompasses a number of identities, including psychic and social ones. During the late Victorian and early Edwardian period, masculinity as a construct underwent many changes, which affected notions of work, property ownership, sexuality, as well as power struggle with men-rivals and women. The concept of 'manliness' became a new moral code as well as a social imperative. Embracing this ideal was a challenging and testing experience for many men as they negotiated power, privilege and status in both the private and the public spheres of life. The Edwardian age, a transitional time in British history, became preoccupied with the consequences of the Boer Wars, gender formation, imperial policy, economic changes and many other factors. This article explores the paradigms of English masculinity and the construction of male identity as a cultural signifier in Arthur Conan Doyle's novel The Hound of the Baskervilles and its Russian film adaptation by Igor Maslennikov. Doyle contextualizes multiple facets of masculinity from the normative to the transgressive, from the private to the public, as well as from the effeminate to the manly as his characters are affected by the anxieties and tensions of their society. After an in-depth analysis of manhood in the novel, the focus of the article shifts to Maslennikov's adaptation and its cinematic use of the literary text, as the film interrogates masculine codes of behavior, relationships with women and the male power struggle represented in the novel. The film becomes a visual interpretation and a powerful enhancement of the narrative's tensions and concerns.
\end{abstract}


Keywords: Arthur Conan Doyle, The Hound of the Baskervilles, Igor Maslennikov, masculinity, manhood, anxiety, identity, film adaptation, power, gender, behavior

The definition of masculinity as a construct changes over time, depending on social expectations, ruling ideologies, religious beliefs, and many other factors. Masculinity is not defined by specific behavior or actions; it is a construction of power structures in social and cultural discourses. Richard Dyer once stated, "masculinity is a bit like air - you breathe it in all the time, but you aren't aware of it much" (28). However, masculinity is not a natural process but a cultural construct, embracing a range of categories of the masculine. The traditional models of masculinity create characteristics that are seen as primarily male characteristics. Among these traits are the endurance of pain or loss, daring and violence, an achievement of power or status at any cost and a suppression of emotions. In their lifetimes individual men undergo tests of manhood and have to accept and/or reject the societal demands imposed on them to locate their own notions of masculinity - their social compromises. For these men, manhood is a "pose that is deeply conflicted, pressured, and forced; a mask of omnipotence and almost obsessive independence," notes David Gilmore (209). A man often becomes estranged from a collective identity and suffers in solitude to achieve his own masculine identity. For many men, such experiences amounted to conflict, "challenge and exertion," according to John Tosh (111).

The aim of this article is to explore the tensions of English masculine identity in The Hound of the Baskervilles by Arthur Conan Doyle and its Russian film adaptation by Igor Maslennikov, in which men often feel entrapped by emotional, social and psychological roles imposed upon them during times of economic depression, imperialism and foreign competition. Men are never at ease with changing concepts of masculinity and neither are Doyle's characters. A novel as a linguistic source deals with the representations of masculinity, while a film, as a visual medium becomes a "transposition or translation from one set of conventions for representing the world to another," suggests Michael Klein in his "Introduction: Film and Literature" (in Klein \& Parker 3). Maslennikov's 
adaptation of The Hound of the Baskervilles examines and externalizes concepts tackled in the literary text such as Englishness, control over self and 'Other,' manliness and power struggle.

In nineteenth-century England, masculinity embraced a variety of components, including race, class, and gender. The concept of "manliness," essential to the Victorians, underwent some changes: "To the early Victorian it represented a concern with a successful transition from Christian immaturity to maturity, demonstrated by earnestness, selflessness and integrity; to the late Victorian it stood for neo-Spartan virility as exemplified by stoicism, hardiness and endurance," explains J.A. Mangan (1). For many men it was a necessary code of conduct to define and shape one's identity and one's role in the changing world of late nineteenth century England. The shift during the 1880-1920 period, as Raymond Williams suggests, encompasses "the vision of Englishness": "what it was to be English . . . was defined within very hard trainings, increasingly standardized and masculine institutions" (263). The unpopular Boer Wars of 1899-1902, fears of race degeneration, atavism and criminality, the changing roles of women were among the many concerns of the Edwardians.

In late Victorian and early Edwardian culture, Englishness itself was identified with masculinity and manliness and as such it became an important marker of literature. Fiction of this period addressed the paradigms of English masculinity and its modeling. The combination of virility, manliness and social respectability is explored throughout the works of many writers of the period. Men continue to find themselves trapped by the construct of a "gentleman": a "strict doctrine of male virtue placed tremendous pressure on men, who represented in a sense the purveyors of patriarchal respectability," as Annette Federico notes (56). Englishness as an identity is based upon the ideal of the gentleman and male characters of this period comply with this ideal. In the world of a rising middle class, imperial conquests, shifting gender roles and economic changes, it was getting harder for men to achieve the ideal of being gentlemen. The shift in the ideology of the gentleman leads to the overall "instability in the ideology of masculinity," according to Karen Waters, as men try to resist past expectations and find a more modern 
masculine identity (3). In the personal drama of many men, the social drama of the age becomes illuminated in many works of fiction.

Arthur Conan Doyle's The Hound of the Baskervilles (1901-02) questions the codes of masculinity and English identity not only through the characters of Sherlock Holmes and his companion Dr. John Watson, but also through Sir Henry Baskerville, Jack Stapleton, Selden and other characters. The inheritance of the Baskervilles' estate is at the center of the male power struggle. Unlike in the Victorian age, in the early Edwardian period men's conduct was no longer governed by the importance of one's rank, as the hereditary rank system gave way to one in which economic factors were prevalent. Economic, social and political changes determined status and authority codes for many men. When Sir Charles Baskerville dies in the moors, not only is the inheritance of the Baskerville Hall is at stake, but also the concept of the gentleman. The estate goes to the young Sir Henry Baskerville, the Baronet, who arrives from farming in Canada: "there was something in his steady eye and the quiet assurance of his bearing which indicated the gentleman" (31, my emphasis). The gentleman is a contested form of masculinity, and the ideologies of "chivalry and of the gentleman, negotiated in everything from Idylls of the King to Great Expectations, contributed to the formation of manliness," notes Joseph Kestner in Sherlock's Men (16). Aside from the social component, more importantly, a gentleman remains "a moral ideal open to all who prove themselves worthy," suggests James Adams (42). The Edwardian gentleman is defined not by birth but by conduct, it is essential to separate a true gentleman from someone who just plays the role of a gentleman (such as Stapleton in Doyle's novel). A gentleman commits to a life of work, displays devotion to a code of duty, to one's family and country, and exhibits self-discipline and self-consciousness. Seen at first as a "foreigner," Sir Henry, nevertheless, is a gentleman who possesses physical fortitude and moral integrity.

The Hound of the Baskervilles constitutes, according to Joseph Kestner, "a distillation of the Edwardian mind by demonstrating the effects of the history of masculinity persisting to the modern age, from Sir Hugo Baskerville to his descendant Sir Henry" (Sherlock's Men 130). The young Baronet is a thoroughly English man, a descendant "of that long 
line of high-blooded, fiery, and masterful men. There were pride, valor, and strength in his thick brows, his sensitive nostrils, and his large hazel eyes. ... [he] was at least a comrade for whom one might venture to take a risk with the certainty that he would bravely share it" (Doyle 55-56). Sir Henry possesses not only physical self-reliance but also moral integrity, comradeship and bravery. Sir Henry indeed exemplifies the familiar concept of manliness, including discipline, duty to England and Empire, physical prowess and stamina, generosity of spirit and overall selfimprovement.

In the novel, Sir Henry is presented as a mature, strong, industrious and brave man, very different from the double-faced Jack Stapleton, the son of Rodger Baskerville, Sir Charles's brother, "a small, slim, cleanshaven, prim-faced man, flaxen-haired and lean-jawed" (Doyle 64). He is described by Watson as a "naturalist," "a creature of infinite patience and craft, with a smiling face and a murderous heart" (Doyle 19, 124). Stapleton possesses secrets and undergoes a number of metamorphoses similar to the butterflies he collects: after returning to England, he acquires a new identity, changes his name to Vandeleur and 'becomes' an entomologist. His dark past fits his ancestors: Sir Hugo imprisons a woman for his own pleasure and is later destroyed by the Hound. Significantly, an animal in turn becomes a manifestation of human aggression and violence. Critic Paul Ferguson suggests that Stapleton is "the reincarnation of the dead Sir Hugo down to the physical resemblance" (28). The villain Stapleton indeed becomes Hugo Baskerville's "throwback . . . both physical and spiritual" (Doyle 138). His atrocious crimes include murder, burglary and even incest. By contrast, Sir Henry plans to modernize Baskerville Hall, bringing a "row of electric lamps" and using the innovative power of "Swan and Edison" (Doyle 58). $\mathrm{He}$ is "the possibility for the amoral and villainous Baskervilles to correct their defective predispositions to criminality, abuse of authority and aberrant sexuality," suggests Joseph Kestner (Sherlock's Men 123). Sir Henry as the heir is capable not only of modernizing the estate but also of restoring Baskerville Hall to its moral stability and social progress. 
Conan Doyle complicates the construction of masculinity with the possibility of atavism in the novel. There is an anxiety about the 'atavistic reversion' of manhood ${ }^{1}$ that threatens normative masculinity represented by Sir Henry. Stapleton, an aristocratic descendant, is juxtaposed to Selden, a murderer and escaped convict. Selden's physical description associates him with degeneration: "an evil yellow face, a terrible animal face, all seamed and scored with vile passions. Foul with mire, with a bristling beard, and hung with matted hair, it might well have belonged to one of those old savages who dwelt in the burrows on the hillsides" (Doyle 96). He is indeed a representation of primitive, prehistoric men, capable of committing crimes of "peculiar ferocity and . . . wanton brutality" (Doyle 57). The landscape in the novel too has traces of evolutionary atavism, reminding one of the times when "prehistoric man lived thickly on the moor" (Doyle 69). The travel through the 'savage' moor becomes the "regressive journey backward through time," notes Nils Clausson (72). Selden is the living proof of atavism, which "produces a psychological and moral reversion," according to Lawrence Frank, while Stapleton, in his primitive regression to crime, exhibits the perversion of normative masculinity in the novel (343).

Doubles function as a metaphor for the anxiety and disorientation concerning masculinity in The Hound of the Baskervilles. Selden is mistaken for Sir Henry while wearing Sir Henry's old clothes. It is revealed that Sir Henry's youth is connected to Selden's story. Dr. Watson notes Sir Henry's acute focus on the land of his family and realization of their dark and crime-ridden past: "Baskerville sat for a long time, his eyes fixed upon it, and I read upon his eager face how much it meant to him, this first sight of that strange spot where the men of his blood had . . . left their mark so deep" (Doyle 55). Sir Henry and Selden are both connected to criminality when Stapleton, a criminal, is revealed to be Sir Henry's cousin. The two men are also linked to the moor; however, the only man who has knowledge of the moor is Sherlock Holmes, according to Ferguson (26). Dr. Watson mistakes Holmes for a "man on the moor": "you actually thought that I [Holmes] was the criminal?" (Doyle 122). Sherlock Holmes exhibits the superiority of knowledge by his ability to impersonate his adversaries, yet here the boundaries between the criminal 
and the detective remain blurry. Following Sir Henry, a disguised Stapleton pretends to be Holmes. As Ferguson notes, Holmes is the "champion of rationality, Stapleton, embodies the irrational, or the perversion of the rational faculty" (30). Holmes and Stapleton thus become "two manifestations of a complex, mysterious human nature that may elude explanation," according to Frank (341). These two men are skillful masters of metamorphosis and the imagery of nets unites them as cunning and clever detectives; yet it is Holmes, the voice of science and reason, who is able "to keep [his] hands upon all the strings" (Doyle 163) and follow the threads to solve Stapleton's crimes.

The foggy landscape of the "desolate, lifeless moor" reinforces the ambiguity of the reversed masculinity in the novel. Dr. Watson sees it as an ocean of evolution out of which all forms of life emerged. He nonetheless senses the desolation and disorientation of the culture as "[1]ife has become like that great Grimpen Mire, with little green patches everywhere into which one may sink and with no guide to point the track" (Doyle 73); for men like Watson, the mire is a dangerous and hostile territory. Stapleton, on the contrary, thinks of the moor not as a treacherous but "a wonderful place, ... so vast, and so barren, and, so mysterious," once again underscoring the presence of atavism within himself (Doyle 67). However, not only can the dangerous mire hide secrets but it also "swallows" Stapleton who as a naturalist is aligned with the moor. Stapleton's body is never found on the moors as even nature rejects the sense of closure: "we were never destined to know . . . . Somewhere in the heart of the great Grimpen Mire, down in the foul slime of the huge morass which had sucked him in, this cold and cruel-hearted man is for ever buried" (Doyle 154). Yet as Joseph Kestner explains, the threat posed by "Stapleton's anarchic masculinity . . . is not expunged from the universe" (Detective 40). Stapleton is a constant reminder of the transgressive manhood, criminality and the possibility of moral degeneration. His mysterious fate underscores the anxieties felt by so many Edwardians. Holmes, a man of acuteness and intelligence, becomes the guide who has to clear out the instability and ambiguity of the culture: "We hold several threads in our hands, and the odds are that one or other of them guides us to the truth" (Doyle 45). The order of male power is re- 
established when Sir Henry inherits the estate; however, his nervous breakdown forces him to take a "long journey ... for the restoration of his shattered nerves" (Doyle 156). The status of an aristocrat cannot protect Sir Henry and free him completely from the errors of his ancestors; however, the hope of the young aristocracy restoring the stability of masculinity, social order and English identity glimmers at the end of the novel.

Women complicate the construction of masculinity in the novel; they become simultaneously victimized and destructive. Sir Charles is attacked and killed by the Hound when he goes to meet a woman. Mrs. Barrymore, "a heavy, solid person, ... [with] . . traces of . . some deep sorrow [that] gnaws ... at her heart" (Doyle 80), is related to the criminal Selden. She almost kills Sir Henry when her brother dressed in Sir Henry's clothes is attacked on the moor. Another woman, Miss Stapleton, known as Beryl Garcia, is controlled by her husband Stapleton with no "reference to the lady's own wishes" (Doyle 88). Dr. Watson immediately sees her as 'exotic'; therefore, as a foreign 'Other', she cannot be trusted: "she was darker than any brunette ... in England. ... There is something tropical and exotic about her" (Doyle 70, 76). Even when Beryl tries to save Sir Henry, she is in turn, as Doyle puts it, "tied up" by her husband (164). Finally, Laura Lyons, a woman of "equivocal reputation" (Doyle 106), is persecuted by the ruthless husband she cannot free herself from; later she becomes Stapleton's mistress as he promises her help but in fact "has lied to [her] in every conceivable way" (Doyle 142). She may hold the power of words being a typist but she becomes a "tool in [a man's] hands" (Doyle 142). Female characters reveal the power of male authority: they suffer physical and emotional abuse from men and at the same time threaten and destabilize codes of masculinity. Women, with their potential for being transgressive and dangerous, add to the anxieties felt by men. Men dominate the narrative in The Hound of the Baskervilles and function better without the company of women.

The narrative structure itself suggests the construction of masculine identity in the novel. In a first person narrative, Dr. Watson frames the story by retelling the events of first seven chapters (with other stories in them) as well as including his letters to Holmes and diary notes. It is 
essential that Dr. Watson exhibits masculine control over the narrative as well as Holmes (Doyle 38); he becomes a man of action when he writes: "it would be indeed a triumph for me if I could run him to earth where my master had failed. . . . I swore that it should not be through lack of energy or perseverance that I should miss the chance which Fortune had thrown in my way" (Doyle 114-118). Watson may often be baffled by Holmes's deduction method, however, in this novel it is Watson who conducts the investigation and Holmes intentionally "yields the stage to Watson and withdraws behind the scenes," according to James and John Kissane (358). Nonetheless, the power game is temporary and when Holmes reappears in Chapter 12, his explanation of the events leaves Watson "raw over the deception" Holmes uses on him (Doyle 123). Holmes's method of solving crimes is based "on codes of class, gender and ethnicity," according to Rosemary Jahn, as he reinforces these codes and restores the order (686).

The two men embody different masculinities (didactic, logical Holmes versus simple, honest Watson) and become 'rivals' in the detective game. The detective game is a "military campaign" for Sherlock Holmes, as Sir Henry sees him; he is "a general who is planning a battle" (Doyle 139). Despite being "born to be a man of action . . . to do something energetic," Dr. Watson is "not luminous" but "a conductor of light," without being "a genius" he can stimulate intelligence in others (Doyle 132, 6). Chapter 15 containing Holmes's recounting of the events once again highlights a striking difference in the two men and their detective methods. The supernatural presence of the Hound complicates the rational explanation of events; the mysterious Hound is the symbol of the family curse, the animal becomes the supernatural creation of a human master. Sherlock Holmes expunges the curse and restores reason; he "weighed every particle of evidence, constructed alternative theories, balanced one against the other and made up his mind as to which points were essential and which immaterial" (Doyle 27). Holmes's power of observation reveals the "obvious things which nobody by any chance ever observes" (Doyle 28). A master of disguise, the detective nonetheless "needs facts, and not legends or rumors" (Doyle 132). Holmes saves Sir 
Henry and in a sense England; Sir Henry becomes the new hope for the Baskervilles to protect and safeguard the British masculinity of the 1900s.

The Hound of the Baskervilles' success attracted numerous film and television adaptations. The debate whether adaptation is indeed a process of creating something new or whether it is an inferior imitation of the existent form continues and it often takes the reductive form of the statement, "The movie simply was not as good as the book." Often films do not convey the moral or aesthetic ideas of the novel; however, instead of talking about "loss in translation" from novel to film, one should consider what is gained in the process of adaptation as it is important to differentiate between different media and modes of expression.

Adaptation is an extensive "cinematic transposition of a particular work or works" and has to be studied not only as a product on its own but also as a process of creation and reception, explains Linda Hutcheon (xiv, 7). John Ellis sees adaptations as works that prolong the pleasure of the original work and "repeat the production of a memory" (4-5); adaptation "trades upon the memory of the novel," whether a memory from reading or a general knowledge of the work (3). To make a successful adaptation a director must make the text his/her own. Successful adaptations force readers to rethink how a text operates contextually and theoretically. There is also a "dichotomous thinking that presumes a bitter rivalry between film and literature," since film is often seen as a result of "anxiety of influence," where the adaptation becomes the Oedipal son who slays the source-text as the Father, states Robert Stam in his Introduction to Literature and Film (in Stam \& Raengo 4). Some of the grounds for hostility towards adaptations include "the historical priority" of literature to film and "the specific priority of novels to their adaptations" (Stam in Stam \& Raengo 4). All films (not only adaptations or remakes) are mediated through intertextuality and many adaptations reveal that all of art is derivative on some level.

Stam goes on to foreground the extent to which the cinematic adaptation of a novel is done though various filters, such as "studio style, ideological fashion, political and economic constraints, auteuristic predilections, charismatic stars, cultural values" (in Stam \& Raengo 46). The linguistic energy of literature is turned into the performative energy 
of adaptation. Adaptation thus becomes an interpretation of a filmmaker's reaction to the text and the use of sound and image relevant to the text. The most successful adaptations do so by interpreting and exploiting the source text; the director's own vision allows the film to be "a separate entity, with a life of its own," according to Linda Cahir (97). Looking at both film and novel, the goal of a scholar is not to privilege one over the other but to study them inter-relationally. Cahir points out four qualities, which determine the overall success of a film adaptation: the film should communicate the integral ideas of the source text; the film should "exhibit a collaboration of filmmaking skills"; the adaptation should explore the source work but remain an aesthetic product; lastly, the cinematic production cannot be too "self-governing or independent" of the source text (99)

The Hound of the Baskervilles has been among the favorites of all Holmes-Watson stories for readers and viewers alike. One of the successful foreign productions of The Hound is a 1981 Russian film by Igor Maslennikov, starring Vasily Livanov (Sherlock Holmes) and Vitalii Solomin (Dr. Watson). Due to the film's immediate success in Russia, a permanent set was built in St. Petersburg. Five films were made during the period of 1979 to 1986, and The Hound was made early on with the scenery shots filmed in Russia. In one of the interviews, Vasily Livanov reflects on the film's success: "The Conan Doyle stories had been made into many films before us, but, as I see it, our characters are remarkable in being very human and convincing. This is probably why the British recognized our film to be the best European version of its kind" (Livanov n.p.). The popularity of the Russian adaptation is explained by the Russian fascination with the Edwardian period, English identity and the concept of the androcentric detective who interrogates the culture and its expectations. Director Igor Maslennikov offers his perspective on the appeal of the Sherlock Holmes films in Russia: "Anyone who goes to him feels secure. He is reliable. He is the personification of gentlemanly behavior. Audiences are always in need of someone with those qualities" (qtd. in Haining 89). In the film, Holmes exemplifies the Russian love and perception of Sherlock Holmes, who proves the incapability of the Scotland Yard's police to solve the crime and address the moral issues. 
Livanov plays the role of Holmes whom he envisioned as the "perfect English gentleman" (qtd. in Haining 89). He embodies intellect and intuition and controls the social order in the film.

The period film succeeds in capturing the Edwardian atmosphere of uncertainty in the film through its dialogues, period costumes and elaborate sets. Of the latter, the Baker Street room is gloomy, as are other interiors, which reflect the interplay of light and darkness. The interior of the Baker street rooms shift to a flight of steps leading to a railed gallery with Holmes and Watson's respective bedroom doors. However, the buildings on Baker Street are too ornate for the London of the period due to St. Petersburg's neoclassical and rococo architectural style. The film opens with a few flashbacks revealing the details of Sir Hugo's death followed by Dr. Mortimer's account of the Hound as the protagonists take on the investigation of the mysterious events. Despite a few plot deviations from the novel, the film is visually powerful, paying close attention to details as it captures the instability and anxieties of Edwardian culture. Sir Henry's nervous breakdown at the end coincides with the breakdown in transmission of patriarchal power and despite the lingering hope for recovery, masculine identity remains problematic.

Location shooting, through the use of fog and various camera angles, succeeds in underlining the Gothic gloom of the moors and uncertainty of the bleak future; the fog surrounding the hearth fire of the Baskervilles manor suggests the chaos in the Edwardian culture. There are multiple shots of the Steppes at night as the moors to reinforce their evil and dangerous nature. The film successfully captures the essence of the mysterious Hound as Holmes ponders the implications of human origins, race degeneration and the possibility of the extinction of the human species. As he gazes over the landscape, Holmes "embodies the paradox of the human situation: joined to the world of animals and savage prehistoric people, yet possessed of intellectual capacities that elevate him above his ancestors," in both the novel and the film (Frank 346). With his insight and logic, Holmes remains the only man who knows the moors' hidden danger in the film (it happens in a scene when he is reunited with Watson who earlier mistakes him for a criminal). 
Similarly to the novel, male characters are intentionally interconnected in the film; Selden is linked to Sir Henry (Nikita Mikhalkov) and Stapleton (Oleg Yankovsky) to Holmes in order to reveal the "figurative depths of self ... associated with a primitive past... ha[ve] never disappeared," according to Frank (360). The Mire is presented in the film in Darwinian terms: "The moon shone on it, and it looked like a great shimmering icefield, with the heads of the distant tors as rocks borne upon its surface" (Doyle 147), reinforcing the locale of disorientation and uncertainty as the desolate moor with its primitive huts and graves becomes the battlefield of the forces of good and evil. The future of the Edwardian age is unpredictable and the effective use of foggy landscape in the film reinforces it.

Casting and acting capture the contrast of masculinities in the film. Oleg Yankovsky as Stapleton is a cunning, scheming man, his dark secrets are stapled beneath the proper appearance of a gentleman. Nikita Mikhalkov's Sir Henry, on the other hand, is very much Russian in manner: he provides a temporary comedic relief carrying a banjo and a saddle, or displaying distaste for the traditional English breakfast of oatmeal; he becomes the Russian parody of the American cowboy. Sir Henry is portrayed as a newcomer, whose life is untouched by the "reign of terror in the district" (Doyle 24) yet his fate is connected to the Baskervilles. As Dr. Mortimer reminds us, "the prosperity of ... the poor, bleak countryside depends upon [Sir Henry's] presence" (Doyle 26) and the task of rejuvenating the Hall as well as England belongs to Sir Henry.

There is an unmistakable chemistry rather than rivalry between Sherlock Holmes and Dr. Watson in the film. The voice tones and body language signify friendship and mutual respect. Despite Vasily Livanov's being rather short and slight for a Holmes, he "carries off the character with aplomb" ("Livanov and Solomin" n.p.). His rational nature and an ability to observe every detail are interrupted by occasional outbursts of humor and activity. Livanov wears glasses when reading, his personal addition to the Holmes figure. A few reviewers noted that Livanov is "saddled with the deerstalker/cape combo on almost every exterior scene" ("Livanov and Solomin" n.p.), which enhances his image as a clever detective. Vitalii Solomin as Dr. Watson is a strong young man as 
portrayed by Doyle. He embodies the neat, disciplined and sensible man in his carefully ironed tweed suit. Watson is the foil to the Holmes character in the film. He is often in the dark, waiting to be enlightened by the brighter Holmes. He walks with a "no-nonsense military posture" that is tempered by an air of concern that one might expect from a physician ("Livanov and Solomin" n.p.). Solomin adds a warmer personal touch to the character and is often described by film critics as one of the very best Watsons to ever appear on-screen. Despite a few plot deviations, the film reflects the key concerns for the Edwardians: criminality and justice, primordial sin and the future of English identity are not 'lost in translation' but are metamorphosed in the visual medium. The fate of England remains in the hands of Sir Henry and it is up to him to ensure the safety of his ancestral estate and his country.

Arthur Conan Doyle clearly interrogates masculine identity, Englishness, gender differences and male power struggle. Doyle is preoccupied with the question where and how men are placed on the scale of masculinity. Imperial conquests, the rise of Germany and America, shifting gender roles destabilize legal, sexual and social affiliations for men. The Hound of the Baskervilles questions masculinity in a period "when the voice of the masculine ruling class was particularly dominant in the culture. ... In the Edwardian period Englishness was closely associated with masculinity, and 'manliness' was seen as a dominant characteristic of English literature," according to Anthea Trodd (6-8). The codes of masculinity and English identity are explored in Doyle's novel, from Sir Hugo Baskerville to his heir Sir Henry as well as Sherlock Holmes and Dr. Watson. All men feel the pressures of turbulent times and become more affected by its passage: the mystery behind the Hound as well as Stapleton's identity reinforces the disorientation and tension men experience during this period. Sir Henry, who inherits Baskerville Hall, is a man of moral integrity and reason; he embodies the hope to re-establish a solid male paradigm as a model of English identity and manhood.

Many scholars would agree that a literary work is authentic and distinct, "whose molecular equilibrium is affected when you tamper with its form," as Andre Bazin puts it (19). The cinematic adaptation's aim, Bazin continues, is "to simplify and condense a work from which it 
basically wishes to retain the main characters and situations" (25). A successful adaptation preserves the aesthetic value of a literary work; it does not eliminate but rather reinforces the novel's integrity. Literature has been made more accessible through adaptation, though audience reception is not a criterion of cultural and aesthetic value. Nineteenth century novelists established the supremacy of form, inventing characters and situations; yet it is a work's narrative style that creates the character and imposes him/her on the public consciousness. Therefore, novels are "mythmakers" (23). The adaptation's aim is to simplify and condense a work from which it basically wishes to retain the main characters and situations.

Both Arthur Conan Doyle's novel and Igor Maslennikov's film adaptation become, as Robert Stam sets forth, "communicative utterances, socially situated and historically shaped" (in Stam \& Raengo 10). Multicultural as well as historical representations of masculinity and identity affect the adaptation of the text and are subject to the director's preconceived notions. Yet as Joseph Conrad reminds us, the art of writing is to make us "see," perceive and understand; combined with the "adequacy of vision and talent" of a filmmaker, it reinforces "the quality of an adaptation from literature to film," states Michael Klein (in Klein \& Parker 12). In a way an adaptation becomes another text, "forming part of a broad discursive continuum" (Stam in Stam \& Raengo 10). The Russian film adaptation of Doyle is overall successful: in its interpretations of the source text, the film reinforces the representations of masculinity and expands readers' understanding of the internal conflict which male characters face and struggle with in their relationships with male rivals as well as women, as Great Britain transitions into the new era. The desire for self-fulfillment, the need to find a place in a social niche and adapt to social changes, and the wish to reinvent their identity preoccupy these timeless characters that continue to fascinate readers, viewers and filmmakers alike.

Note:

${ }^{1}$ There is a link of criminality with atavistic behavior, which poses a threat to normative masculinity; for more see Joseph Kestner's chapter "The Edwardian 
Holmes" in Sherlock's Men: Masculinity, Conan Doyle, and Cultural History (122-124).

\section{Works Cited}

Adams, James Eli. Dandies and Desert Saints: Styles of Victorian Masculinity. Ithaca: Cornell UP, 1995. Print.

Bazin, Andre. "Adaptation, or the Cinema as Digest." Film Adaptation. Ed. James Naremore. New Brunswick, NJ: Rutgers UP, 2000. 19-28. Print.

Cahir, Linda C. Literature into Film: Theory and Practical Approaches. Jefferson, NC: McFarland, 2006. Print.

Clausson, Nils. "Degeneration, Fin-de-Siècle Gothic, and the Science of Detection: Arthur Conan Doyle's The Hound of the Baskervilles and the Emergence of the Modern Detective Story." Journal of Narrative Theory 35:1 (Winter 2005): 60-87. Print.

Doyle, Conan Arthur. The Hound of the Baskervilles. London: Penguin, 2001. Print.

Dyer, Richard. "Male Sexuality and the Media." Sexuality of Men. Eds. A. Metcalf and M. Humphries. London: Pluto, 1985. 28-43. Print.

Ellis, John. "The Literary Adaptation: An Introduction.” Screen 23.1 (1982): 3-5. Print.

Federico, Annette. Masculine Identity in Hardy and Gissing. London: Associated UP, 1991. Print.

Ferguson, Paul. "Narrative Vision in The Hound of the Baskervilles." Clues 1 (Fall/Winter 1980): 24-30. Print.

Frank, Lawrence. "The Hound of the Baskervilles, the Man on the Tor, and a Metaphor for the Mind." Nineteenth-Century Literature 54.3 (Dec. 1999): 336-72. Print.

Gilmore, David D. Manhood in the Making: Cultural Concepts of Masculinity. New Haven: Yale UP, 1990. Print.

Haining, Peter. The Television Sherlock Holmes. London: Virgin, 1994. Print.

Hutcheon, Linda. A Theory of Adaptation. New York: Routledge, 2006. Print.

Jahn, Rosemary. Detecting Social Order. New York: Twayne, 1995.

Kestner, Joseph. The Edwardian Detective, 1901-15. Vermont: Ashgate, 2000. Print.

- - -. Sherlock's Men: Masculinity, Conan Doyle, and Cultural History. Vermont: Ashgate, 1997. Print.

Kissane, James, and John Kissane. "Sherlock Holmes and the Ritual of Reason." Nineteenth-Century Fiction. 17.4 (Mar. 1963): 353-62. Print.

Klein, Michael, and Gillian Parker. The English Novel and the Movies. New York: Ungar, 1981. Print.

Livanov, Vasily. Interview. Lifestyle: A Russia Journal Publication 2.45 (24 Jan. 2000), n. p. Web. 1 Oct. 2014. 
Mangan, James A., and James Walvin, eds. Manliness and Morality: MiddleClass Masculinity in Britain and America, 1800-1940. New York: St. Martin's, 1987. Print.

Stam, Robert, and Alessandra Raengo, eds. Literature and Film. A Guide to the Theory and Practice of Film Adaptation. Malden, MA: Blackwell, 2005. Print.

Tosh, John. A Man's Place: Masculinity and the Middle-Class Home in Victorian England. New Haven: Yale UP, 1999. Print.

Trodd, Anthea. A Reader's Guide to Edwardian Literature. Calgary, Canada: U of Calgary P, 1991. Print.

"Vasily Livanov and Vitaly Solomin: The Russian Sherlock Holmes and Doctor Watson.” 2010. Web. 1 Oct. 2014.

Waters, Karen. The Perfect Gentleman: Masculine Control in Victorian Men's Fiction, 1870-1901. New York: Lang, 1997. Print.

Williams, Raymond. Politics and Letters. London: New Left, 1979. Print. 